\title{
O TRANSPLANTE SOB A ÓPTICA DE UM JORNAL DIÁRIO
}

\author{
Transplantation reported by a newspaper
}

Priscila Pavani, Wilma Aparecida Nunes, Cristiane Aparecida Melicardi

\section{RESUMO:}

O transplante de órgãos como terapêutica tem se beneficiado de avanços científicos e proporcionado melhor qualidade de vida para o receptor, reduzindo as complicações do doador e atingindo um grau de eficiência com taxa de mortalidade nula ou quase nula. É uma modalidade de tratamento inovadora e bastante divulgada, que envolve aspectos éticos, morais, religiosos, culturais e legais, que constituem algumas barreiras para sua prática efetiva. Objetivo: verificar o conteúdo das informações que são veiculadas pelo jornal "Folha de São Paulo" abordando o tema "transplante". Método: Pesquisa documental, retrospectiva, através da publicação , utilizando como termo de busca a palavra "transplante". O período analisado foi de 1994 a 2005. Resultados: Foram selecionadas 2134 reportagens do jornal. O editorial com maior número de reportagens foi "Cotidiano" e os aspectos mais divulgados foram aqueles referentes às descobertas, fila única e legislação, evidenciando a clara preocupação com o texto da lei, aperfeiçoada ao longo dos anos. Conclusões: Nas reportagens, são revelados os dilemas de um sistema de saúde sobrecarregado pela demanda, com grandes dificuldades para organizar-se internamente para atender as necessidades da população de um país com dimensões continentais, onde emergem ilhas de excelência, mas fica à margem grande parte dos potenciais beneficiados pela terapêutica. Visível também é o impacto dos meios de comunicação sobre os valores de um povo ainda carente de formação e informação necessários para assumir sua cidadania e reivindicar seus direitos, atingido por uma avalanche de contradições que emergem com essa nova tecnologia de tratamento.

Descritores: Transplante, Artigo de Jornal, Doação de órgão, Sistemas de Saúde, Terapêutica

Instituição:

Faculdade de Enfermagem - Centro de Ciências da Vida - Pontifícia Universidade Católica de Campinas - São Paulo - SP.

Correspondência:

Priscila Pavani

Rua Holanda, 174 - Jardim Celani

CEP: 133326-150 - Salto - SP

Tel: 11 9921-0399

E-mail: priscila.pavanii@gmail.com

Recebido em: 27.06.2007

Aceito em: 27.07.2007

\section{INTRODUÇÃO:}

John Hunter em 1778 utilizou pela primeira vez o termo "transplante", quando descreveu suas experiências com enxertos de ovários e testículos em animais desconhecidos. A grande contribuição técnica para os transplantes surgiu no Século XIV, quando Carrel e Guthrie desenvolveram a técnica de sutura de vasos sangüíneos. Nesse mesmo século, Ullmann removeu o rim de um cachorro e o manteve funcionando por vários dias no corpo de outro cachorro. Em 1909, Unger transplantou um rim de macaco para uma criança que sofria de insuficiência renal aguda. Mas foi Guthrie quem fez uma descoberta crucial: através de suas experiências com transplantes renais, observou que os órgãos morriam após um tempo; sugeriu que a causa de tal fenômeno poderia estar relacionada à resposta imunológica. ${ }^{1}$ As primeiras tentativas de transplante remontam ao Século XVIII, quando ele se limitava à transfusão de sangue mal sucedida, inicialmente, devido à falta de conhecimento da compatibilidade sangüínea; outro aspecto relevante é o fato desse tipo de procedimento ser menos afetado por questões legais e filosóficas, como acontece com o transplante de órgãos sólidos como rim, pulmão, fígado e outros. ${ }^{2}$

Os avanços da tecnologia, a instituição de cuidados adequados e o conceito de morte definido por critérios neurológicos (conhecimento da morte do cérebro) passaram a ser fatores necessários para determinar a morte, que deixou de ser conceituada como a cessação da circulação e da respiração. Os dispositivos, como a ventilação mecânica e o suporte hemodinâmico permitem 
manter o funcionamento do sistema cardiorrespiratório, e tal fato torna necessário determinar critérios para diagnosticar a morte cerebral, de maneira que essa constatação não seja realizada de maneira empírica e acriteriosa. ${ }^{3}$

A definição de morte encefálica está amparada em uma série de avaliações que colocam em evidência um aspecto fundamental da clínica, qual seja o fato do procedimento ser útil para o diagnóstico ou prognóstico do paciente; independentemente desta definição, trata-se de uma metodologia segura, e os conhecimentos disponíveis são suficientes para caracterizar um doador de órgãos. ${ }^{4}$

Ajustar os conceitos, a legislação, procedimentos enriquecidos com novas descobertas e condutas no âmbito dos profissionais de saúde tem sido um desafio, mas tal desafio toma proporções incalculáveis quando o foco da questão é a divulgação da informação para a população em geral. Estudo recente constata o significativo desconhecimento do tema entre universitários e infere que, se nos espaços onde os processos de divulgação da informação são amplamente utilizados a situação é precária, para a população a desinformação é muito maior. Para sanar o problema, os autores sugerem campanhas utilizando os meios de comunicação. ${ }^{5}$

Existem diversas formas de comunicação, entre elas a escrita, e uma das expressões mais populares de comunicação escrita é o jornal. Esse tipo de veículo de informação foi introduzido no país por Hipólito José da Costa Pereira, considerado também fundador do jornalismo brasileiro, por sua atuação como editor do mensário Correio Braziliense (1808-1822). Tratava-se de publicação de cunho político, que abriu espaço para a informação de natureza científica, com o primeiro número datado de 1 de junho de $1808 .^{6}$

O Jornal pode ser definido como processo de transmissão de informações, através de veículos de difusão coletiva, com características específicas de atualidade; afinal, o jornal vive do cotidiano, do presente, da periodicidade; é o enunciado da notícia contemporânea, instrumento do público, ao alcance de todos, que poderá ser usado por qualquer pessoa para a recepção de informações. Existem funções básicas para o jornal, que compreendem as vertentes política, educativa, econômica e social, além do entretenimento?

O interesse jornalístico pelo informe científico é recente. A primeira edição do primeiro jornal americano chamado Public Occurrences, editado por Benjamim Harris, datada de 25 de setembro de 1960, compilou os itens para informar os colonos de Massachussets sobre o que estava acontecendo e para abafar vários informes falsos, maliciosamente espalhados entre eles. A publicação divulgava temas de saúde pública e medicina. Considerando-se o especial interesse das pessoas, principalmente em relação à sua própria saúde, foi fácil para os repórteres científicos reconhecerem que o noticiário sobre problemas de saúde e medicina garantia uma atração especial para a maioria dos leitores. ${ }^{8}$

Com o aumento crescente do interesse da população por assuntos relacionados às descobertas científicas e avanços tecnológicos, os jornais, revistas e televisão vislumbraram nesses temas um importante foco para atingir o público e passaram a elaborar e divulgar mais reportagens nessa área, com uma linguagem adaptada e veiculada para pessoas leigas. Se antes as notícias, reportagens e entrevistas relacionadas à ciência e tecnologia, eram discutidas em salas fechadas ou em conferências, com a democratização da informação e o interesse manifesto na sociedade, os cientistas dispuseram-se a divulgar suas descobertas, permitindo assim que ouvintes pudessem formular suas próprias opiniões sobre assuntos muitas vezes polêmicos. ${ }^{9}$

O transplante de órgão é uma modalidade terapêutica inovadora, que vem despertando cada vez mais o interesse público. Trata-se de procedimentos que estão sendo aperfeiçoados com novas pesquisas e descobertas, que redimensionam as condutas e demandam atualização na legislação, pois atingem valores alicerçados no âmago da sociedade. Essa forma de tratamento evidencia uma grande conquista da ciência a serviço do homem. porque tem sido um recurso utilizado para a manutenção imediata da vida; é uma técnica que se revela, cada vez mais, como um instrumento precioso da prática médica e da preservação da vida humana. Entretanto, o transplante pode provocar reações contraditórias, como o fascínio pela cura, mas também inquietação. O seu êxtase decorre da perspectiva de vida que ele proporciona às pessoas ameaçadas pela falência de um órgão ou tecido. A inquietação ocorre porque a transferência com maior freqüência de elementos (órgão ou tecido) obtidos a partir de indivíduo morto proporciona o confronto com a imagem do que seja a própria morte ou vida. Outro sentimento que aflora com freqüência é a angústia daqueles que esperam por um órgão, conscientes de que sua vida pode se perder durante a espera. ${ }^{10}$

Trata-se de um procedimento que poderá ampliar seus benefícios se a população contribuir. Mas, qual é a informação que chega ao povo? Em face dessa realidade, o objetivo desse estudo foi verificar o conteúdo das informações veiculadas pelo jornal "Folha de S. Paulo" abordando o tema "transplante".

\section{OBJETIVOS}

Verificar o conteúdo das informações veiculadas pelo jornal "Folha de S. Paulo" abordando o tema "transplante". Identificar quais os assuntos de maior incidência nas matérias publicadas e os editoriais escolhidos para publicação.

\section{MÉTODOS}

Este é um estudo documental, descritivo, retrospectivo e com coleta de dados de fonte primária (jornal Folha de $\mathrm{S}$. Paulo). $\mathrm{O}$ acesso às informações foi via on-line, no site: www.uol.folhadesaopaulo.com. br utilizando o termo de busca "transplante". Foram identificadas 2134 reportagens contendo o termo "transplante", publicadas entre 1994 a 2005. Destas, foram selecionados 157 artigos versando sobre temas diretamente vinculados ao transplante em humanos. Os artigos foram impressos e arquivados de acordo com o conteúdo das reportagens, para posterior análise.

\section{RESULTADOS}

As reportagens selecionadas foram distribuídas de acordo com os editoriais. Observa-se, no gráfico 1 como se destaca o editorial Cotidiano (antes chamado de Cidades), que teve início em 17 de fevereiro de 1991, no qual as reportagens são elaboradas para prover informação para o público leigo. Houve significativo aumento do número de reportagens na década de noventa, e o tema legislação teve destaque substancial nos meios de comunicação. Tal fato justifica a conformação do gráfico 2, mostrando que o número de reportagens sobre transplantes está bastante elevado nos anos de 1997 e 1998. 
Gráfico 1: Distribuição de reportagens selecionadas no Jornal Folha de S. Paulo contendo o termo "transplante" de acordo com o editorial, Campinas SP, 2006.

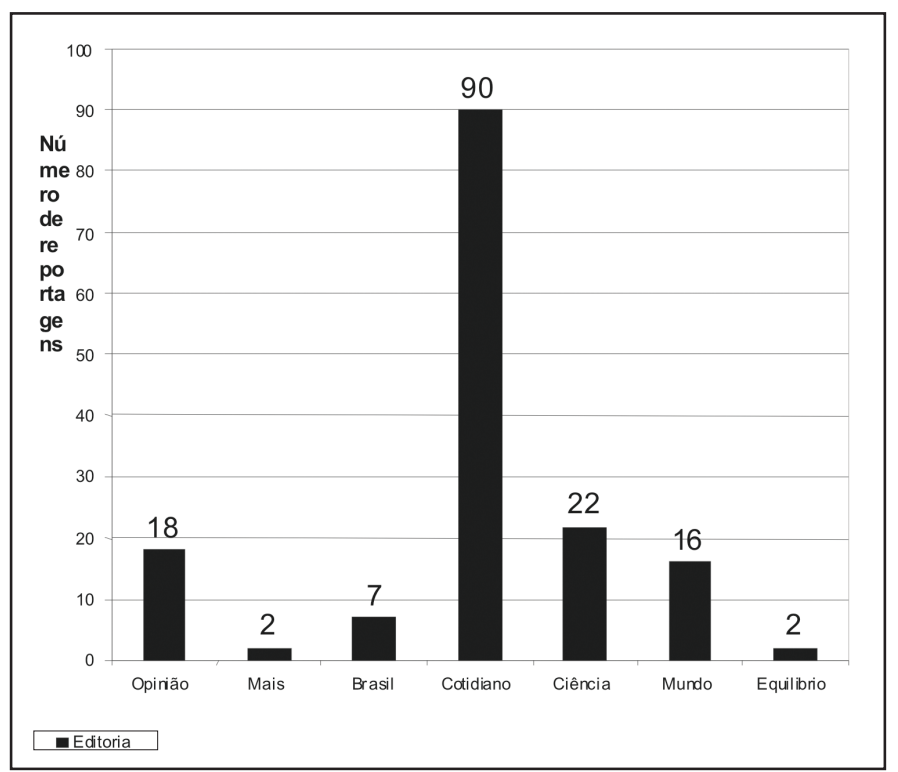

Fonte: Jornal Folha de S. Paulo

Gráfico 2: Distribuição das reportagens selecionadas no jornal Folha de $S$ Paulo contendo o termo "transplante" de acordo com o tema, Campinas SP, 2006.

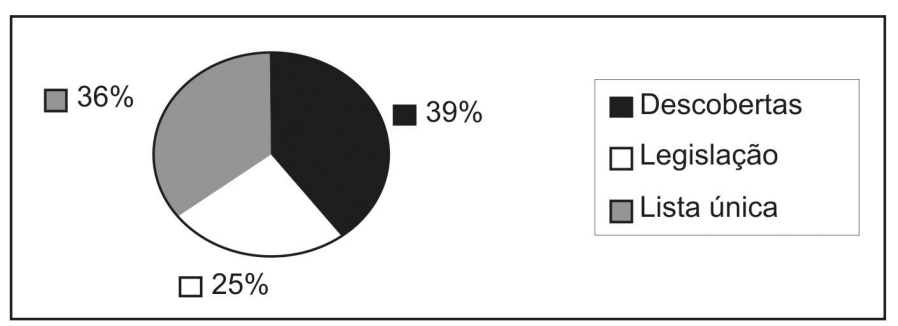

Fonte: Jornal Folha de S. Paulo

Notícias que apresentam novas tecnologias, inovações e aperfeiçoamento da técnica foram catalogadas no grupo das descobertas, juntamente com a lista única - sistema montado no país para organizar os serviços de captação e distribuição de órgãos, visando atender prioritariamente pacientes mais suscetíveis - são os temas predominantes nas reportagens publicadas no editorial Cotidiano, conforme demonstra o gráfico 3. Dos textos agrupados no item "Descobertas", foram selecionados 29 artigos, cujo foco tem sido o transplante de célula-tronco (graf. 4).

As leis que regulamentam a política de doação de órgãos e tecidos no país têm sofrido, nos últimos 30 anos, uma série de alterações que culminaram não apenas em uma mudança conceitual, mas, sobretudo, definiram as responsabilidades do Estado e dos envolvidos no processo de doação/transplante.

Outro tema veiculado pelo jornal foi denominado "Lista única de espera" para transplantes. Neste item, foram catalogadas 26 reportagens referentes ao assunto "Lista única, captação e distribuição de órgãos".
Gráfico 3: Distribuição das reportagens do Jornal Folha de S. Paulo inseridas no assunto "descobertas", Campinas - SP, 2006.

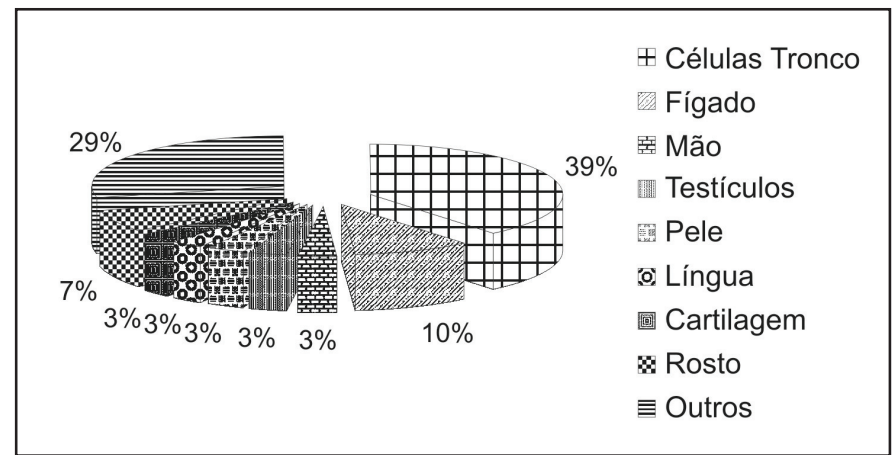

Fonte: Jornal Folha de S. Paulo

Gráfico 4: Distribuição das reportagens selecionadas no Jornal Folha de S. Paulo sobre "legislação" de acordo com o ano de publicação, Campinas SP, 2006.

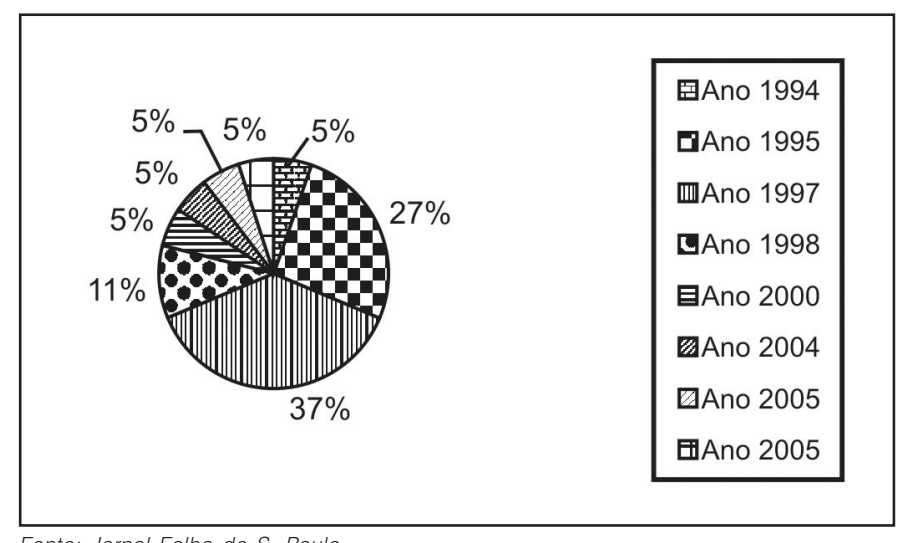

Fonte: Jornal Folha de S. Paulo

\section{DISCUSSÃO}

No editorial Cotidiano as notícias têm como objetivo a popularização das informações, com narrativas claras, utilizando palavras usuais, com um texto composto para fácil entendimento, ou seja, recorrendo a uma linguagem corriqueira e mais assimilável para retratar os fatos, neste caso, que tratam de transplantes, e passam a ser do interesse da população em geral. O jornal é um produto construído a cada dia, sua agilidade e eficiência ao informar são fundamentais para assegurar a atualidade e credibilidade do próprio jornal; com isso, os leitores, que são os clientes potenciais, buscam essas informações escritas de maneira informal, concisa e de mais fácil compreensão. ${ }^{11}$ O editorial Ciência reforça o fascínio e a credibilidade do leitor pelas descobertas no campo da saúde, do funcionamento do corpo, da cura das doenças e do prolongamento da vida. ${ }^{12}$

A votação, no Congresso Nacional, de quatro de fevereiro em 1997, do texto de lei 434/1997, que tratava de doação de órgãos, foi motivo de extenso questionamento na mídia. De acordo com aquela lei, passou a ser considerado doador todo aquele que, em vida, não houvesse manifestado vontade em contrário. ${ }^{13}$

A predominância do tema transplante de células-tronco é conseqüência de uma onda de pesquisas que colocaram esse material biológico (células indiferenciadas que possuem capacidade de se diferenciar e 
de se tornar altamente especializadas) como um dos mais fascinantes avanços da medicina na virada do Século XX. O uso de célulastronco é uma modalidade terapêutica muito promissora e estudos demonstram resultados encorajadores, principalmente para doenças que acometem a medula óssea, como a leucemia. Através da melhor compreensão no uso de células-tronco, tem sido possível intervir em estados patológicos que antes eram considerados irreversíveis. ${ }^{14}$

A segunda modalidade de transplante mais citada nos textos é o transplante de fígado intervivos. O transplante hepático intervivos é uma técnica adotada em crianças. A escassez de doadores cadavéricos estimulou a realização de transplante hepático intervivos inicialmente em crianças e posteriormente em adultos; no entanto a espera por um fígado entre adultos também é bastante longa, motivo pelo qual a indicação de transplante intervivos está aumentando. No Brasil, o número de transplantes hepáticos intervivos aumentou de seis em 1997 para 177 em 2003. ${ }^{15}$

A primeira lei brasileira sobre doação e transplante de órgãos data de 1968, quando da definição dos critérios clínicos do diagnóstico de morte encefálica. Durante quase 30 anos, de 1968 a 1997, a atividade de transplante era pouco regulamentada (normalmente havia regulamentações locais ou regionais) e desenvolvida com bastante informalidade, no que diz respeito à inscrição de receptores, ordem de transplante, retirada de órgãos e também aos critérios de distribuição dos órgãos captados. ${ }^{16}$

No início da década de 90 foi sancionada a lei no 8.489 , de 19/11/92, regulamentando os transplantes no Brasil. Essa lei ainda não contemplava os critérios para diagnóstico de morte encefálica, cadastro técnico de equipes, hospitais transplantadores e pacientes receptores, fazendo com que inúmeras discussões e pesquisas envolvendo o tema fossem realizadas. Em 1997, foi publicada a Lei 9.434, regulamentada pelo Decreto Federal no 2.268/97, que dispõe sobre a remoção de órgãos, tecidos e partes do corpo humano para fins de transplante e tratamento, revogando a lei 8.489/92. ${ }^{17}$

Embora prevista em lei, na prática, os procedimentos afastam-se do conceito de igualdade e justiça, ou seja, os critérios para inclusão na lista única geram polêmica e se mostram ineficazes para colocar pessoas em situações desiguais em condições de igualdade na espera. ${ }^{18}$

A morte é um evento após o qual podemos esperar que ocorra agonia, angústia e desgosto. Essa mistura de sentimentos deve ser considerada durante o processo de doação. Após a confirmação do diagnóstico de morte cerebral é que se inicia o processo de doação. Os coordenadores de transplante, na maioria enfermeiros, fazem entrevista familiar para autorização da doação. Para manifestação do consentimento, é necessário que os familiares tenham todas as dúvidas sanadas sobre o processo de doação, principalmente, e até mais importante, sobre morte encefálica. ${ }^{19}$

A família, apontada como elemento-chave para a sobrevivência dos indivíduos em espera, que é responsável pela proteção e socialização de seus componentes, transmissão de capital cultural e econômico do grupo, bem como das relações de gênero e de solidariedade entre gerações, pode ser lançada de repente em uma situação complexa de tomada de decisão, porque tem obrigação de pronunciar-se sobre um assunto jamais abordado no círculo familiar, onde opiniões podem ser divergentes. ${ }^{20}$

Características demográficas, socioeconômicas e culturais têm sido relacionadas com diferentes prevalências de intenção para doar órgão dentre a população. Maiores taxas de recusa à doação têm sido relacionadas a indivíduos com maior religiosidade, apesar de nenhuma religião ser contrária à doação de órgãos. ${ }^{21}$ As religiões católica romana, budista, hindu, muçulmana e protestante são favoráveis à doação, classificando-a como um ato de generosidade. Na religião judaica há perspectivas sobre a doação, porém não tão claras. ${ }^{22}$

\section{CONCLUSÕES}

O Jornal é instrumento destinado a popularizar a informação e expor os dilemas bioéticos que emergem da aplicabilidade dos avanços científicos. É imprescindível que sejam divulgados os recursos terapêuticos disponíveis, seus riscos, custos, benefícios e implicações decorrentes de sua aplicabilidade em linguagem acessível e adaptada ao leigo. O transplante de órgãos coloca em evidência uma série de questões, porque revela as inúmeras faces de um procedimento cuja trajetória está permeada de indefinições que atingem valores sociais. Nesse sentido, é urgente a necessidade de aperfeiçoar a legislação vigente, a fim de reduzir a limites mínimos as práticas ilícitas, e promover a justa oportunidade de estender os benefícios dessa nova terapêutica a todos aqueles que dela necessitam, sem ferir os valores morais e éticos do transplantado e do doador, respeitando os princípios fundamentais que regem o exercício profissional dos trabalhadores da saúde.

\section{ABSTRACT}

Organ transplant as therapy has been benefited from scientific advancements, providing a better quality of life to the receptor, reducing donor complications, and even reaching an efficiency degree that attains a null or almost null mortality rate. This is an innovatory and well spread treatment modality that involves ethical, moral, religious, cultural, and legal aspects which establishes some barriers for its practice in an effective way. Purpose: The purpose of this study was to verify the content of information published by the newspaper "Folha de São Paulo" approaching the subject "transplants". Methods: The methodology used was the documental retrospective research of online publications using the word "transplant" as searched term; the period evaluated was from 1994 to 2005. Results: As result, 2,134 newspaper's articles were selected - the "daily" editorial that presented a higher amount of articles and the most spread subjects were those related to the findings, the single queue and the legislation, evidencing a clear concern on the text of the law, which was improved along the years. Conclusion: The dilemmas posed by an overcharged health system to cope with the demand and which deals with great difficulties to attain an internal organization to meet the population's needs of a country of continental dimensions are disclosed, where islands of excellence emerge; however, a major part of potential persons who could benefit themselves from such therapy is left aside. Added to this, it is clear the impact of the media on the values of a people still in need of more education and information to assume its citizenship and claim their rights.

Keywords: Transplantation, Health System, Therapeutics. 


\section{REFERÊNCIAS:}

1. Pereira W.A. Manual de transplantes de órgãos e tecidos. São Paulo: Loyola, 2004.

2. Lamb D. Transplante de órgãos e ética. São Paulo: Hucitec; 2004.

3. Sullivan J, Seem D, e Chabalewski F. "Detemining Brain Death”. Critical Care Nurse. 1999;19(2):37-45

4. Levyman C. "Morte Encefálica - Revisão e Propostas". Jornal Brasileiro de Transplantes. 2005;8(1):333-40.

5. Santos ZMSA, Capistrano AP, Oliveira VLM, Neto JDS. Doação de Órgãos sob a Óptica do Estudante Universitário. Jornal Brasileiro de Transplantes. 2005;8(1):320-4

6. Guimarães E. Produção e circulação do conhecimento. São Paulo: Pontes; 2001

7. Amaral L. Jornalismo: matéria de primeira página. Rio de Janeiro: Tempo Brasileiro, 1986

8. Krieghbawn, H. Ciência e os meios de comunicação de massa. Rio de Janeiro: Correio da Manhã, 1970.

9. Manente MEP. O texto de ciência e tecnologia nos magazines semanais: uma análise semiótico-discursiva. Mestrado em comunicação e semiótica da Pontifícia Universidade Católica de São Paulo, 2003.

10. Campos, HH. "Aumento do Número de Transplantes e da Doação de Órgãos e Tecidos: Processo de Construção Coletiva". Jornal Brasileiro de Transplantes. 2005;8(2):230-3

11. Rozados, HBF. "O Jornal e o seu Banco de Dados: uma Simbiose Obrigatória" Ciência e Informática. 1997;26(1):12-4

12. Lage EA, Freitas MIF, Acúrcio FA. "Informação sobre Medicamentos na Imprensa um Uso de forma Racional?”. Ciência Saúde Coletiva. 2005;10:133-139.
13. Brasil. Lei $N^{\circ} 9434$ de 4 fevereiro de 1997, que dispõe sobre a remoção de órgãos, tecidos e parte do corpo Humano para fins de transplante e tratamento e dá outra previdências. Diário Oficial [da] República Federativa do Brasil. Brasília, 4 de fev. 1997. Seção I, p.191.

14. Mota ACA, Soares MBP, Santos RR. "Uso de Terapia Regenerativa com Célulastronco da Medula Óssea em Doenças Cardiovasculares - Perspectivas do Hematologista”. Revista Brasileira de Hematologia, 2005;27(2):126-132.

15. Coelho JCU, Parolin MB. "Qualidade de Vida do Doador após Transplante Hepático Intervivos". 2005;42(2):83

16. Roza BA. Efeitos do Processo de Doação de Órgãos e Tecidos em Familiares: Intencionalidade de uma nova doação. São Paulo, 2005. Tese doutorado. Universidade Federal de São Paulo, 146p

17. Guerra CICO, Bittar OJN. "O Custo que Envolve a Retirada de Múltiplos Órgãos". Revista da Associação Médica Brasileira. 2002;48(2):156-162.

18. Messias E., Skotozko C E. "Psychiatric Assessment in Transplantation". Revista de Saúde Pública. 2000;34(4):415- 440.

19. Santos MJ, Massarollo, MCKB. "Processo de Doação de Órgãos: Percepção de Familiares de Doadores Cadáveres". Revista Latino-americana de Enfermagem, 2005;13(3):382-387.

20. Steiner P. "A Doação de Órgãos: a Lei, o Mercado e as Famílias”. Tempo Social. 2004;12(2):25.

21. Barcellos F.C. "Intenção de Doar Órgãos em uma População Adulta”. Pelotas, 2003. Dissertação de mestrado. Universidade Federal de Pelotas.

22. Padrão M.B, Lima A.A.F, Moraes E.L. "Fatores que Influenciam a Recusa Familiar no Processo de Doação de Órgãos e Tecidos para Transplantes”. Jornal Brasileiro de Transplantes. 2004,7(3):32 